\title{
Karakteristik Sarang Penyu HiJau (Chelonia mydas) di Pulau Kasiak KaWasan Konservasi Penangkaran Penyu Pariaman, Sumatera Barat
}

\section{Characteristic Of Nesting AREa OF Chelonia Mydas IN THE CONSERVATION AREA IN ISLAND, WEST SUMATERA}

\author{
Desi Nova Sari'), Muhammad Fauzi' ${ }^{1}$, Eni Sumiarsih' ${ }^{1)}$ \\ ${ }^{1}$ Manajemen Sumberdaya Perairan Fakultas Perikanan dan Kelautan,Universitas Riau, J1. HR Soebrantas \\ Km 12,5 Simpang Baru, Panam-Pekanbaru Indonsia 28293 \\ Correspondence Author:mfauzi.pku@gmail.com
}

\section{ARTICLE INFO}

Submitted: 07 April 2018

Revised : 13 Mei 2018

Approved: 16 Juni 2018

\section{Kata kunci:}

Penyu hijau, repreduksi penyu hijau, sarang penyu, migrasi penyu hijau

\begin{abstract}
Abstrac
The research aimed to understand the nesting area characteristic of C. mydas in the Kasiak Island was conducted from March-April 2017, coincidence with the nesting time of green turtle. Observation of the nesting area of green turtle was conducted in the Northern, Southern, Western and Eastern parts of the island. Parameters studied were the slope of the beach, the distance between the water edge during the high tide and the nest, sand texture, types of vegetations around the nest, number of nests present and the quality of water around the island. Results shown that the coast's slope ranged from 1.74 to $2.89^{\circ}$, the distance between the water edge during the high tide and the nest ranged from 1.17 to $1.70 \mathrm{~m}$, the substrate texture was dominated by sand $(>90 \%)$, silt (3.4-7.25\%) and clay (2-8\%). The nest temperature was $25-32^{\circ} \mathrm{C}$, nest humidity was $30-40 \%$ and the common vegetation was Thespesia populnea. Quality of the water around the Kasiak Island are as follows: temperature was $29-30^{\circ} \mathrm{C}$, salinity was from 33-34\%o, current speedwas 0.4-0.5 m/s and $\mathrm{pH}$ was 8 .
\end{abstract}

\begin{abstract}
Abstrak
Penelitian ini bertujuan untuk mengetahui karakteristik area tempat bertelur penyu hijau (Chelonia mydas) di Pulau Kasiak yang meliputi kemiringan pantai, jarak sarang dari rata-rata pasang tertinggi air laut, tekstur pasir, suhu dan kelembaban sarang, jenis vegetasi, jumlah sarang dan kualitas perairan. Penelitian ini telah dilaksanakan pada Maret-April 2017 dan dibagi menjadi 4 lokasi pengamatan yang berdasarkan arah mata angin. Metode penelitian adalah metode survei. Hasil penelitian menunjukkan bahwa kemiringan pantai $1,74-2,89^{\circ} \mathrm{C}$, jarak sarang dari rata-rata pasang tertinggi air laut $1,17-1,70 \mathrm{~m}$, tekstur pasir yaitu $>90 \%$ pasir, debu 3,4-7,25 \% dan liat 2-8 \%, suhu sarang $25-32^{\circ} \mathrm{C}$, kelembaban sarang 30-40 \%, jenis vegetasi yang dominan adalah tumbuhan waru laut (Thespesia populnea). Kondisi lingkungan perairan sekitar Pulau Kasiak yaitu suhu air laut $29-30^{\circ} \mathrm{C}$, salinitas $33-34 \%$, kecepatan arus berkisar 0,4-0,5 m/s, $\mathrm{pH} 8$.
\end{abstract}




\section{PENDAHULUAN}

Pulau Kasiak merupakan salah satu pulau yang ada di Kota Pariaman, Sumatera Barat yang memiliki luas 1,595 ha. Pulau Kasiak terletak pada koordinat $00^{\circ} 35^{\prime} 44-00^{\circ} 35^{\prime} 48,3$ ' ' LS dan $100^{\circ}$ 0,4' 28,4' - $100^{\circ} 0,4^{\prime} 31,9$ ' ' BT dengan jarak dari Kota Pariaman berkisar 30-45 menit. Pulau Kasiak sebagai tempat peneluran penyu hijau, Pulau Kasiak memiliki habitat berpasir halus, bersih, luas 2,16 hektar sebagai tempat yang baik bagi penyu hijau untuk bertelur. Di perairan Indonesia sering dijumpai penyu, diantaranya Penyu Hijau (Chelonia mydas), Penyu Sisik (Eretmochelys imbracata), Penyu Lekang (Lepidochelys olivacea), Penyu dan Penyu Belimbing (Dermochelys coriacea) (Yusuf, 2011). Di Pariaman, Sumatera Barat ditemukan lokasi persarangan penyu diantaranya pada wilayah Sumatera Barat terdapat beberapa lokasi persarangan penyu. Lokasi persarangan penyu ditemukan di Pulau Penyu, Pulau Karabak Ketek, Pulau Karabak Gadang di Kabupaten Pesisir Selatan. Pada wilayah Kota Padang terdapat pada Pulau Toran dan Pulau Pandan. Di Kabupaten Padang Pariaman ditemui pada Pulau Pieh dan Pulau Kasiak. Hampir diseluruh pulau-pulau tersebut terdapat lokasi peneluran bagi penyu hijau dan penyu sisik (Harfiandri, 2000). Pada pulau Jemur Provinsi Riau hanya ditemukan penyu hijau yang ditemui melakukan peneluran (Feliatra et $a l .$, 2004). Hal demikian juga ditemui di Pulau Kasiak yaitu seringnya ditemui penyu hijau bertelur. Dapat diduga karakteristik pulau-pulau tertentu lebih cocok sebagai tempat bertelurnya jenis penyu tertentu. Oleh karena itu, karakteristik Pulau Kasiak sebagai tempat peneluran penyu hijau penting diteliti.

\section{METODOLOGI PENELITIAN Waktu dan Tempat}

Penelitian ini dilaksanakan pada bulan Maret-April 2017 yang bertempat di Pulau Kasiak Kawasan Konservasi Penangkaran Penyu Pariaman Sumatera
Barat. Metode yang digunakan adalah metode survei dengan melakukan pengamatan langsung, analisis data ditabulasikan dalam bentuk tabel dan grafik. Data primer yang diperoleh dibandingkan beberapa literatur menurut para ahli.

\section{Prosedur Penelitian \\ Pengukuran Kemiringan Pantai}

Kemiringan pantai diukur dengan menggunakan meteran roll $100 \mathrm{~m}$ dan tongkat berskala serta mistar segitiga.

\section{Pengukuran Karakteristik Sarang}

Karakteristik sarang dengan di amati ada atau tidak cekungan seukuran tubuh penyu (body fit) setelah itu ada tidaknya penyu hijau juga dilihat dari jejak yang ditinggalkan.

\section{Suhu Sarang}

Pengukuran suhu dilakukan dengan mengunakan thermometer pada pasir sarang penyu.

\section{Kelembaban Sarang}

Pengukuran kelembaban pasir sarang dilakukan dengan menggunakan Soil Moisture. Untuk pengukuran kelembaban sama seperti pengukuran suhu.

\section{Tekstur Pasir Peneluran}

Pengambilan contoh substrat (pasir) dilakukan dengan menggunakan sendok semen dan kantong plastik yang berukuran 500 gr.

\section{Jarak Sarang dari Pasang Tertinggi}

Jarak sarang diukur dari batas tertinggi hingga titik pusat sarang yang dituju dimana telur-telur diletakkan, dilakukan secara acak dan diukur dengan satuan feet dengan cara menghitung jumlah langkah normal.

\section{Jenis Vegetasi}

Pengamatan jenis vegetasi diamati secara visual, jenis yang diamati dicatat kedalam log book penelitian. Kemudian 
diamati apakah sarang peneluran penyu hijau berada disekitar vegetasi.

\section{Jumlah Sarang, Jumlah Telur}

Jumlah sarang penyu hijau yang diamati selama penelitian ditulis didalam $\log$ book sedangkan jumlah telur didapat dari data sekunder dari Kawasan Penangkaran Konservasi Penyu Pariaman Sumatera Barat. Pengukuran sarang, lebar dan kedalaman sarang langsung dilakukan dilapangan.

\section{Pengukuran Parameter Kualitas Perairan}

Pengukuran parameter kualitas air meliputi parameter fisika dan kimia meliputi suhu, kecepatan arus, salinitas, kecepatan arus dan derajat keasaman $(\mathrm{pH})$.

\section{Suhu}

Metode yang digunakan pada pengukuran suhu adalah metode pemuaian.

\section{Salinitas}

Pengukuran salinitas dilakukan dengan menggunakan handrefractometer.

\section{HASIL DAN PEMBAHASAN}

Secara Administrasi Pulau Kasiak termasuk dalam Kecamatan Pariaman Utara yang tidak berpenduduk dan terletak tepat di sebelah Barat Kota Pariaman. Masyarakat sekitar memanfaatkan Pulau Kasiak sebagai tempat pariwisata. Pulau Kasiak dapat dicapai melalui jalur laut dengan menggunakan kapal sewa dengan kapasitas mesin $10 \mathrm{PK}$, dengan waktu perjalanan \pm 25 menit dari UPT Konservasi Penyu.

Pulau Kasiak merupakan salah satu pulau yang berhadapan langsung dengan Samudera Hindia. Tipe pasang surut di Sumatera Barat sangat dipengaruhi oleh pasang surut di Samudra Hindia. Pulau Kasiak memiliki kekayaan sumberdaya alam hayati yang tinggi, di antaranya Pulau Kasiak merupakan Habitat Peneluran Penyu, disamping itu Pulau Kasiak juga memiliki hamparan terumbu karang yang luas, memilki substrat pasir yang unik. Pantainya ditutupi oleh hamparan pecahan cangkang mollusca yang sudah mati yang berasal dari laut lepas dan terbawa ombak, sehingga membentuk pantai yang unik, dan alami.

\section{Karakteristik Pulau Kasiak Tempat Peneluran Penyu Hijau}

\section{Kemiringan Pantai di PulauKasiak}

Karakteristik pada Pulau Kasiak pada bagian utara, kemiringannya adalah $2,59^{\circ}$ dan pada bagian selatan kemiringannya mencapai 2,89 , sedangkan pada bagian timur mencapai $2,51^{\circ}$,dan pada bagian barat pulau kemiringannya adalah $1,74^{0}$. Titik pengamatan kemiringan pantai sesuai dengan arah mata angin. Pada bagian utara dikoordinat $0^{0} 35^{\prime} 43,98^{\prime}$ ' LS $-100^{\circ}$ 4'30,65', BT. Lokasi 1 Pada bagian selatan titik pengamatan $0^{0} 35^{\prime}, 48,702$ ', LS - $100^{\circ} 4^{\prime} 30,834^{\prime} \mathrm{BT}$, pada bagian timur titik pengamatan $0^{0} 35^{\prime} 41,90^{\prime}$ ' $\mathrm{LS}-100^{\circ}$ 4'26,85' BT dan pada bagian barat pada titik pengamatan $0^{0} 35^{\prime} 44,65^{\prime}, \mathrm{LS}-100^{\circ}$ 4'32,034', BT (Tabel 1).

Kemiringan pantai Pulau Kasiak bervariasi yaitu $1,74-2,89^{\circ}$ (Gambar. 1 dan 2). Apabila dilihat dari kemiringan tersebut menunjukkan bahwa daerah pantai pada kemiringannya adalah landai. Pada bagian Barat Pulau Kasiak kemiringan pantai dibawah $2^{0}$ selebihnya diatas $2^{0}$.

Pada penelitian ini ditemukan tiga sarang penyu, dua (2) sarang penyu ditemukan pada bagian Timur dan satu (1) sarang ditemukan pada bagian Barat Pulau Kasiak Tabel (2). Namun pada bagian Barat Pulau Kasiak sarang penyu yang tidak terdapat telur, diduga sarang tersebut salah satu upaya penyu hijau untuk menghindari dari predator yaitu dengan cara membuat sarang kosong. Perbedaan tiga (3) jumlah sarang yang ditemukan pada setiap lokasi disebabkan oleh beberapa faktor, diantaranya perbedaan 
kelandaian pantai dan adanya perbedaan vegetasi.

Tabel 1.Titik Koordinat dan Kemiringan Pantai pada Setiap Sarang yang Ditemukan di Pulau Kasiak

\begin{tabular}{|c|c|c|c|c|}
\hline Lokasi & itik Koordinat & $\begin{array}{c}\begin{array}{c}\text { Jumla } \\
\text { h }\end{array} \\
\text { Sarang }\end{array}$ & $\begin{array}{l}\text { Kemiri } \\
\operatorname{ngan}\left({ }^{0}\right)\end{array}$ & Kriteria \\
\hline 1 & $\begin{array}{c}0^{0} 35^{\prime} 43,98^{\prime}, \\
\text { LS }-100^{0} \\
4^{\prime} 30,65^{\prime}, \mathrm{BT} \\
0^{0} 35^{\prime}\end{array}$ & - & 2,59 & $\begin{array}{l}\text { Pantai } \\
\text { landai }\end{array}$ \\
\hline 2 & $\begin{array}{c}48,702 \text { ' LS - } \\
100^{0} \\
4{ }^{\prime} 30,834^{\prime}, \\
\text { BT }\end{array}$ & - & 2,89 & $\begin{array}{l}\text { Pantai } \\
\text { landai }\end{array}$ \\
\hline 3 & $\begin{array}{c}0^{0} 35^{\prime} 41,90^{\prime \prime} \\
\text { LS - } 100^{\circ} \\
4^{\prime} 26,85^{\prime}, \mathrm{BT}\end{array}$ & 2 & 2,51 & $\begin{array}{l}\text { Pantai } \\
\text { landai }\end{array}$ \\
\hline 4 & $\begin{array}{c}\text { LS - } 100^{0} \\
\text { 4'32,034', } \\
\text { BT }\end{array}$ & 1 & 1,74 & $\begin{array}{c}\text { Pantai } \\
\text { datar }\end{array}$ \\
\hline
\end{tabular}

\section{Sumber : Data Pribadi}

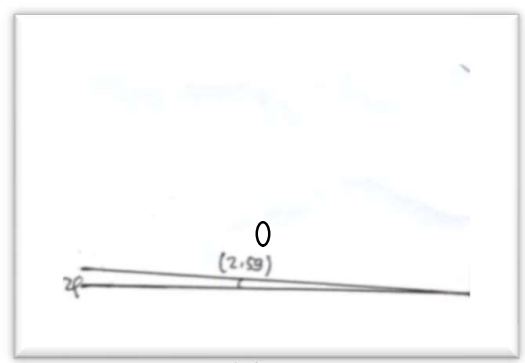

(a)

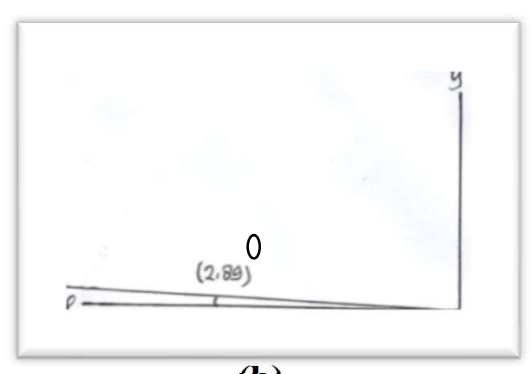

(b)

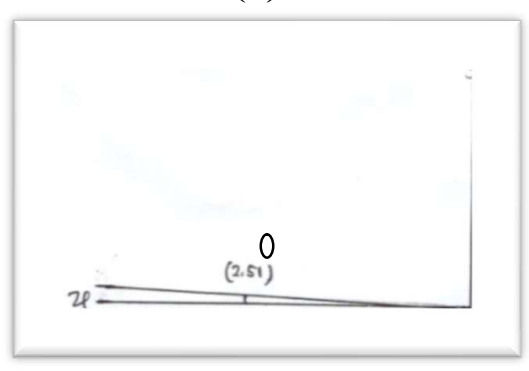

(c)

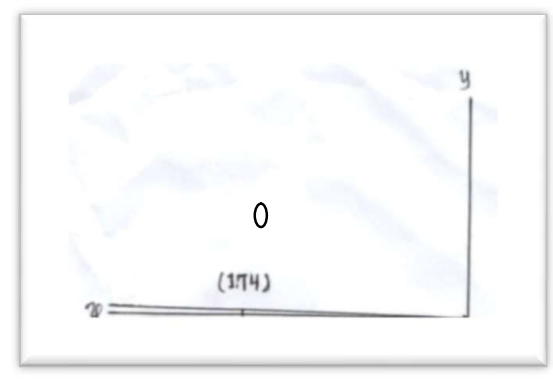

Gambar 1. (a) Kemiringan Pantai pada lokasi 1, (b) Kemiringan Pantai pada lokasi 2, (c) Kemiringan Pantai pada lokasi 3, (d) Kemiringan Pantai pada lokasi 4.

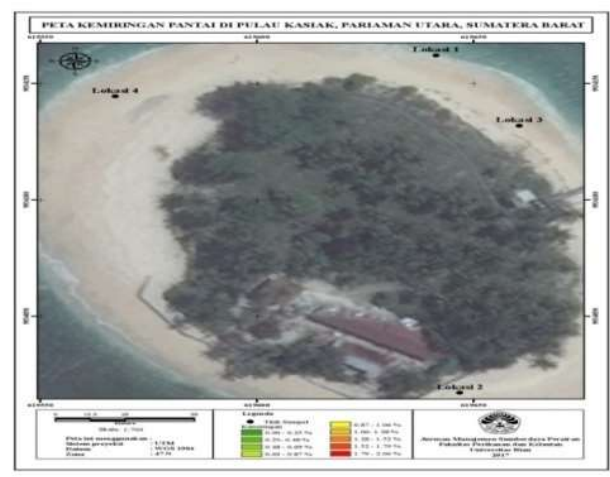

Sumber : Dokumentasi Pribadi

Gambar 2. Peta Kemiringan Pantai di Pulau Kasiak

Secara keseluruhan kemiringan pantai pada lokasi 1, 2 dan lokasi 3 di Pulau Kasiak termasuk pantai yang landai dan pantai yang disukai penyu hijau untuk bertelur. Namun lokasi satu (1) terdapat aktivitas tempat pemberhentian kapal/speatboat, sehingga menyebabkan kurangnya penyu hijau yang melakukan peneluran disana. Sedangkan pada lokasi dua (2) hanya tempat persinggahan penyu hijau, karena lokasi ini dekat dari batas pasang tertinggi, sehingga tidak ditemukannya sarang telur penyu hijau (Gambar 6).

Secara keseluruhan kemiringan pantai pada lokasi 1,2 dan lokasi 3 di Pulau Kasiak termasuk pantai yang landai dan pantai yang disukai penyu hijau untuk bertelur. Namun lokasi satu (1) terdapat aktivitas tempat pemberhentian kapal/speatboat, sehingga menyebabkan kurangnya penyu hijau yang melakukan 
peneluran disana. Sedangkan pada lokasi dua (2) hanya tempat persinggahan penyu hijau, karena lokasi ini dekat dari batas pasang tertinggi, sehingga tidak ditemukannya sarang telur penyu hijau (Gambar 6).

Lokasi tiga (3) kemiringan pantainya tidak jauh berbeda pada lokasi satu (1) dan dua (2), tetapi pada lokasi ini ditemukan dua (2) sarang bertelur penyu hijau. Secara keseluruhan lokasi tiga (3) merupakan lokasi yang banyak ditemukan sarang penyu hijau dibandingkan lokasi lain. Pada lokasi tiga (3) merupakan hamparan pasir yang luas dan relatif alami. Pada lokasi empat (4) memiliki pantai yang datar dan dekat dengan pasang tertinggi.

\section{Jarak Sarang dari Pasang Tertinggi}

Penyu hijau yang berada di Pulau Kasiak meletakkan sarangnya ditempat yang tidak dipengaruhi oleh air pasang. Pada sarang satu (1) letak sarangnya berjarak $1,17 \mathrm{~m}$ dari pasang tertinggi. Sarang dua (2) terletak antara 1,65 m dari batas pasang tertinggi Tabel (2), sedangkan sarang ke tiga (3) terletak 1,70 $\mathrm{m}$ dari batas pasang tertinggi.

Tabel 2. Jarak Sarang dari Pasang Tertinggi ke Arah Darat

\begin{tabular}{|c|c|c|}
\hline Sarang & $\begin{array}{l}\text { JPT } \\
(\mathrm{m})\end{array}$ & Keterangan \\
\hline 1 & 1,17 & $\begin{array}{l}\text { Sarang dinaungi oleh oleh } \\
\text { beberapa vegetasi seperti waru } \\
\text { laut (Thespesia populnea). }\end{array}$ \\
\hline 2 & 1,65 & $\begin{array}{l}\text { Sarang terkena langsung oleh } \\
\text { cahaya matahari. Di sekitar } \\
\text { sarang terdapat tumbuhan } \\
\text { perdu. }\end{array}$ \\
\hline 3 & 1,70 & $\begin{array}{l}\text { Di sekitar sarang terdapat } \\
\text { pecahan cangkang dan karang }\end{array}$ \\
\hline & & JPT : (Jarak Pasang Tertinggi) \\
\hline
\end{tabular}

Sarang peneluran penyu hijau yang ditemukan di Pulau Kasiak berada relatif dari garis pantai dan cenderung menggali sarang diantara akar-akar tumbuhan perdu dan waru laut (Thespesia populnea). Sarang seperti ini ditemukan di lokasi tiga (3) yang terdapat dua (2) sarang peneluran penyu hijau. Kemudian sarang penyu hijau juga ditemukan di daerah yang bebas naungan yaitu pada lokasi empat (4), tetapi sarang yang ditemukan tersebut tidak terdapat telur didalamnya.

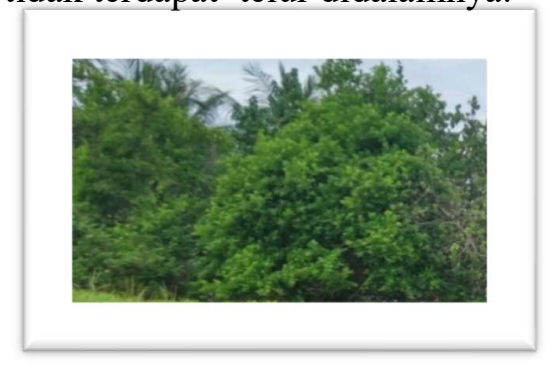

(a) Waru Laut

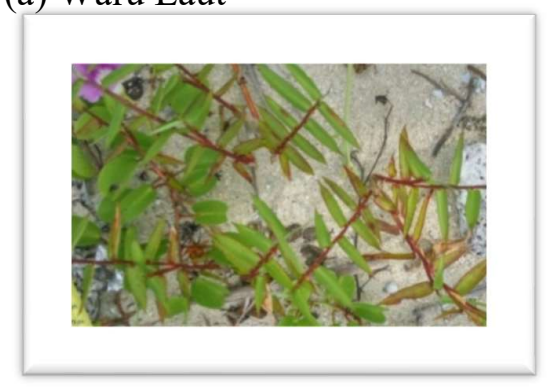

(b) Tumbuhan Perdu

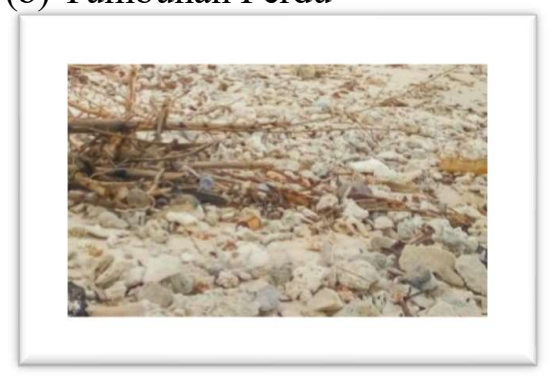

(c) Pecahan Cangkang dan Karang

Gambar 3. Jenis Vegetasi, Pecahan Cangkang dan Karang di Pulau Kasiak

Terdapat perbedaan vegetasi disetiap sarang penyu hijau yang ditemukan di Pulau Kasiak. Sarang satu (1) berada dibawah naungan vegetasi pohon waru laut (Thespesia populnea). Sarang dua (2) ditemukan pada vegetasi tumbuhan perdu, sedangkan sarang tiga (3) ditemukan di kawasan yang tidak terdapat vegetasi (bebas naungan), tetapi terdapat pecahan cangkang dan karang. Habitat peneluran penyu hijau di Pulau Kasiak didominasi oleh vegetasi jenis waru laut (Thespesia populnea). Sedangkan vegetasi tempat peneluran penyu hijau di Pantai Sindangkerta 
Tasikmalaya didominasi oleh vegetasi pandan laut (Thespesia populnea) (Sani, 2000).

Vegetasi yang ada di Pulau Kasiak ini merupakan vegetasi yang disukai oleh penyu hijau meletakkan sarang untuk bertelur, ditandai oleh ditemukannya sarang peneluran penyu hijau berada dibawah naungan vegetasi tumbuhan waru laut (Thespesia populnea). Sedangkan di lokasi yang tidak ada vegetasinya hanya ditemukan sarang kosong, diduga sarang tersebut salah satu upaya penyu hijau untuk menghindari dari predator yaitu dengan cara membuat sarang kosong.

\section{Tekstur Pasir Peneluran di Pulau Kasiak}

Tekstur dan persentase pasir sangat berpengaruh pada preferensi peneluran penyu hijau. Komposisi tekstur substrat pada lokasi Pulau Kasiak terdiri dari pasir, debu dan liat. Tekstur substrat dibagi menjadi dua pengamatan yaitu substrat pantai dalam sarang dan luar sarang, kandungan pasir itu dalam sarang $85,28-87,18 \%$ dan luar sarang 94,82$95,72 \%$, sedangkan tekstur debu dalam sarang, $18-7,25 \%$ dan luar sarang 3,4-3,9\% dan sebagian kecil komposisi substrat itu terdapat liat dalam sarang $8 \%$ dan luar sarang $2 \%$ Tabel (3).

Tabel. 3. Komposisi Tekstur Subtrat

\begin{tabular}{ccccccc}
\hline & \multicolumn{3}{c}{ Komposisi Tekstur Subtrat (\%) } \\
\cline { 2 - 7 } Lok & \multicolumn{2}{c}{ Pasir } & \multicolumn{2}{c}{ Debu } & \multicolumn{2}{c}{ Liat } \\
asi & Dala & Luar & Dala & Luar & Dala & Luar \\
& $\begin{array}{c}\text { Sara } \\
\text { ng }\end{array}$ & $\begin{array}{c}\text { Sara } \\
\text { ng }\end{array}$ & $\begin{array}{c}\text { Sara } \\
\text { ng }\end{array}$ & $\begin{array}{c}\text { Sara } \\
\text { ng }\end{array}$ & $\begin{array}{c}\text { sara } \\
\text { ng }\end{array}$ & $\begin{array}{c}\text { Sara } \\
\text { ng }\end{array}$ \\
\cline { 2 - 7 } 3 & 85,2 & 94,8 & 7,18 & 3,4 & 8 & 2 \\
& 8 & 2 & & & & \\
& 87,1 & 95,7 & 7,25 & 3,9 & 8 & 2 \\
\hline
\end{tabular}

Sumber : Data Pribadi

Susunan substrat pantai Pulau Kasiak daerah peneluran penyu hijau secara keseluruhan berupa pasir dengan komposisi tekstur substrat $>90 \%$. Susunan tekstur substrat seperti ini umumnya disukai oleh penyu hijau untuk bertelur. Menurut Nuitja (1978;1992), bahwa susunan tekstur daerah peneluran penyu hijau berupa pasir tidak kurang dari $90 \%$ dan sisanya adalah debu dan liat. Selanjutnya Novitawati et al., (2003) menyatakan bahwa beberapa habitat alaminya penyu hijau memilih pantai peneluran yang didominasi oleh pasir sedang dan halus (Tabel. 3)

Tekstur pasir sarang peneluran penyu hijau di Pulau Kasiak merupakan tekstur pasir yang disukai oleh penyu untuk bertelur. karena tekstur pasir yang ada di Pulau Kasiak $>90 \%$ ini artinya Pulau Kasiak didominasi oleh pasir, ini merupakan pantai yang disukai oleh penyu untuk bertelur.

\section{Keadaan Sarang Penyu Hijau di Pulau Kasiak}

Selama penelitian suhu sarang penyu hijau di Pulau Kasiak pagi hari $29,5-32,2^{\circ} \mathrm{C}$, siang hari $26,2-29,3^{\circ} \mathrm{C}$ dan pada sore hari $26,3-30,5^{\circ} \mathrm{C}$ (Gambar 4).

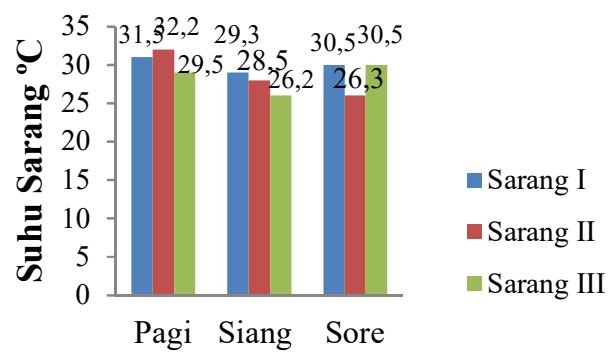

Waktu Pengamatan

Gambar 4. Suhu Sarang Penyu Hijau di Pulau Kasiak

\section{Kelembaban Sarang Penyu Hijau}

Kelembaban sarang peneluran penyu hijau selama penelitian dengan waktu pengukuran pagi, siang dan sore hari berbeda-beda yaitu pada pagi hari kelembaban sarang 34,5-40,0\%, pada siang hari kelembaban sarang 32,7-34,5\% dan pada sore hari 30,2-36\% (Gambar 5). 


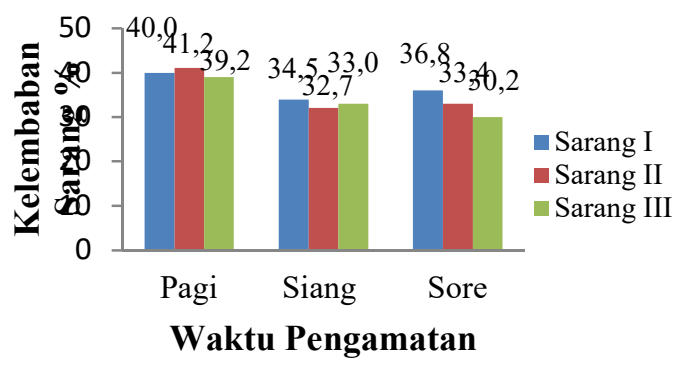

Gambar 5. Kelembaban Sarang Penyu Hijau

Secara keseluruhan kisaran kelembaban sarang peneluran penyu hijau di Pulau Kasiak merupakan kelembaban yang sesuai untuk peneluran penyu hijau dan kelembaban sarang ini merupakan faktor pendukung untuk pertumbuhan embrio telur penyu dan penetasan penyu hijau.

\section{Jumlah Sarang Telur Penyu Hijau di Pulau Kasiak}

Selama penelitian jumlah sarang yang ditemukan sebanyak tiga (3) sarang, dua (2) berisi telur dan satu (1) dan sarang tidak ada telur. Jumlah telur penyu hijau pada sarang satu (1) dengan jumlah 155 butir dan kedalaman sarang antara 60-80 dan lebar sarang 27-40 cm, dan yang terendah terdapat pada sarang dua (2) dengan jumlah 135 butir kedalaman sarang 55-70 dan lebar sarang $23-35 \mathrm{~cm}$.

\section{Parameter Kualitas Air di Pulau} Kasiak

Hasil pengukuran kualitas air di Pulau Kasiak selama penelitian, suhu 29$30^{\circ}$, salinitas 33-34\%o, kecepatan arus 0,4$0,6 \mathrm{~m} / \mathrm{s}$ dan nilai $\mathrm{pH}$ disemua titik sampling yaitu 8 Tabel (4).

Tabel 4. Hasil pengukuran Kualitas Air di Pulau Kasiak

\begin{tabular}{ccccc}
\hline Titik & \multicolumn{4}{c}{ Pengukuran Kualitas Air } \\
\cline { 2 - 5 } $\begin{array}{c}\text { Sampli } \\
\text { ng }\end{array}$ & $\begin{array}{c}\text { Suhu }^{0} \\
\text { C }\end{array}$ & $\begin{array}{c}\text { Salinita } \\
\text { s (\%) }\end{array}$ & $\begin{array}{c}\text { Kec. Arus } \\
(\mathrm{m} / \mathrm{s})\end{array}$ & $\mathrm{pH}$ \\
\hline 1 & 29 & 33 & 0,4 & 8 \\
2 & 30 & 33 & 0,5 & 8 \\
3 & 30 & 34 & 0,5 & 8 \\
\hline Rata & 29,6 & 33,3 & 0,46 & 8 \\
\hline
\end{tabular}

Sumber : Data Pribadi
Hasil pengukuran kualitas air pada titik sampling tidak jauh berbeda, ini karena kondisi disetiap titik sampling tidak jauh berbeda. Suhu menjadi faktor yang sangat berperan dalam proses fisiologi bagi seluruh organism, baik pada ikan maupun mamalia laut. Suhu juga berperan dalam persebaran biota di perairan. Berdasarkan sebaran horizontal suhu air di Pulau Kasiak Tabel (6) terlihat ada variasi dengan nilai tertinggi $30^{\circ} \mathrm{C}$ dan terendah $29^{\circ} \mathrm{C}$. Hal ini menunjukkan bahwa kisaran suhu air laut di kawasan ini masih dalam kisaran normal untuk ukuran rata-rata suhu perairan laut di Indonesia dan masih menunjang untuk biota dan pembentukan terumbu karang. Kualitas perairan masing-masing lokasi penelitian tidak terdapat perbedaan yang mencolok, karena lokasi penelitian yang tidak terlalu luas. Secara umum faktor fisika kimia perairan Pulau Kasiak masih menunjukkan kisaran yang mendukung kehidupan biota laut perairan.

\section{KESIMPULAN}

Karakteristik sarang penyu hijau (Chelonia mydas) di Pulau Kasiak Kawasan Konservasi Penangkaran Penyu Pariaman Sumatera Barat adalah kemiringan pantai $1,74-2,89^{\circ}$ dan letak sarang pada jarak pasang tertinggi 1,17$1,70 \mathrm{~m}$, vegetasi yang dominan ditemukan pada sarang penyu hijau (Chelonia mydas) di Pulau Kasiak adalah tumbuhan waru laut (Thespesia populnea), tekstur pasir yaitu $>90 \%$ pasir) selebihnya debu $(3,4-$ $7,25)$ dan liat $(2-8)$, suhu sarang penyu hijau $25-32^{\circ} \mathrm{C}$, dan kelembaban suhu sarang penyu hijau 30-40 \%.

Kondisi lingkungan perairan sekitar Pulau Kasiak yaitu suhu air laut $29-30^{\circ} \mathrm{C}$, salinitas 33-34\%o, kecepatan arus 0,4-0,5 $\mathrm{m} / \mathrm{s}$, sedangkan $\mathrm{pH} 8$, menunjukkan bahwa habitat yang sangat sesuai untuk penyu hijau bertelur serta kondisi lingkungan yang normal dan mendukung untuk biota perairan. 
SARAN

Disarankan adanya penelitian lanjutan mengenai karakteristik habitat peneluran penyu hijau (Chelonia mydas) di pulau lain dengan mengamati parameter kimia dan biologinya dan dalam pemilihan waktu penelitian, sebaiknya melihat juga pada waktu musim bertelurnya.

Penjagaan yang lebih intensif perlu dilakukan pada setiap lokasi peneluran penyu, baik di luar di wilayah konservasi maupun wilayah lainnya dan meningkatkan upaya pelestarian penyu, yang dapat membangkitkan kesadaran masyarakat tentang pentingnya menjaga dan melestarikan penyu sebagai salah satu hewan dilindungi yang hampir punah keberadaannya.

\section{UCAPAN TERIMA KASIH}

Terima kasih kepada dosen pembimbing saya bapak Dr. Muhammad Fauzi, S.Pi, M.Si dan Ibu Dr.Ir. Eni Sumiarsih, M.Sc, dan Kak Ika Fitria Hasibuan, S.Pi., M.Si terima kasih kepada pihak UPT Konservasi Penyu dan kepada teman-teman saya yang banyak membantu saat di lapangan (Dwi Pitriani, S.Pi, Tiur Maulina Hutagalung S.Pi, Tria Indriasih, S.Pi dan Meylani Sitinjak, S.Pi).

\section{DAFTAR ACUAN}

Damanhuri, H. 2007. Keberadaan Penyu dan Upaya Pelestariannya di Sumatera Barat. http://www.Bunghatta. Info/tulisan.php?dw.206. (Diakses tanggal 19 Mei 2017)
Feliatra, F., M. Fauzi, D. Efizon, R. Rusliadi., 2004. Model Konservasi Penyu Hijau di Pulau Jemur Kabupaten Rokan Hilir, Provinsi Riau. Konas IV Pengelolaan Sumberdaya Perairan Umum, Pesisir Dan Laut.

Novitawati, I., A.M. Thohari, A. Priyono dan I. S. Suwelo., 2003. Kajian Potensi Habitat Peneluran Penyu di Pantai Taman Wisata Alam Sukawayana, Pelabuhan Ratu, Kabupaten Sukabumi. Departemen Konservasi Sumberdaya Hutan. Fakultas Kehutanan. Institut Pertanian Bogor. Hal 181.

Nuitja, I.N.S, 1992. Biologi dan Ekologi Pelestarian Penyu Laut. IPB press. Bogor.

Sani, A.A.,2000. Karakteristik Biofisik Habitat Peneluran dun Hubungannya dengan Sarang Peneluran Penyu Hijau (Chelonia mydas) di Pantai Sindang Kerta, Cipatujah, Tasikmalaya, Jawa Barat. (Skripsi). Departemen Ilmu dan TeknologiKelautan. Fakultas Perikanan dan Ilmu Kelautan. Institut Pertanian Bogor. Bogor.

Yusuf, A., 2000. Mengenal Penyu. Yayasan Aalam Lestari dan K eidnren Nature Conservation

\section{E-mail :}

desinovasari12@gmail.com

mfauzi.pku@gmail.com

enisaf@yahoo.co.id 